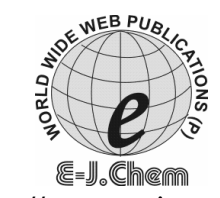

http://www.e-journals.net
ISSN: 0973-4945; CODEN ECJHAO

E-Journal of Chemistry

2009, 6(S1), S47- S52

\title{
Spectrophotometric Evaluation of Stability Constants of Copper, Cobalt, Nickel and Zinc with 2-Thiobarbituric Acid in Aqueous Solution
}

\author{
F.AHMADI ${ }^{*}$, A.H M.SARRAFI and M.M.GHASHGHAEE ${ }^{\S}$ \\ Chemistry Department, Gachsaran Azad Univercity, Gachsaran, Iran. \\ ${ }^{\S}$ Young Researchers Club, Gachsaran Azad University, Gachsaran, Iran. \\ ahmadi@iaug.ac.ir
}

Received 23 December 2008; Accepted 20 February 2009

\begin{abstract}
Stoichiometry and equilibrium study of ion-ligand conducted in aqueous solution by spectrophotometry. Stability constants of the complexes are determined at $25{ }^{\circ} \mathrm{C}$, ionic strength was adjusted to $0.2(\% \mathrm{w} / \mathrm{v})$ with $\mathrm{NaCl}$. The $\mathrm{pH}$ was adjusted to 6. 2-Thiobarbituric acid-ion complexes' stability was calculated in aqueous solution using DATAN (Data Analysis program). The results of this method denote formation specie $\mathrm{ML}_{2}$. The $\log \mathrm{K}$ for ions $\mathrm{Cu}^{+2}, \mathrm{Co}^{+2}, \mathrm{Ni}^{+2}$ and $\mathrm{Zn}^{+2}$ were $4.89,4.69,4.47$ and 4.82 , respectively.
\end{abstract}

Keywords: 2-Thiobarbituric acid (TBA), Spectrophotometric, Stability constant, DATAN.

\section{Introduction}

Determination of thermodynamic parameters of complexes using potentiometric or spectrophotometric data is a challenging problem to develop and propose new method for selective and sensitized determination of trace amounts of ions. Their stability constants can be of significance in order to predict different chemical processes such as isolation, extraction, or preconcentration methods ${ }^{1,2}$, since many elements present in trace amounts can be isolated by complexing reagents. The magnitude of stability constant indicates the particular level of tolerance to the interference by other species. The stability constant depends on several parameters such as the electronegativity, hard or soft of the donor atoms in ligand structure, topology of ligand and the ionic radial, charge, hard or soft of the metal ion and its atomic number ${ }^{3}$.

Nowadays, different programs such as $\mathrm{KINFIT}^{4}, \mathrm{BEST}^{5}$ and $\mathrm{DATAN}^{6}$ have been used for evaluating the stability constant of complexes or dissociation constant of ligands, using the spectrophotometric or potentiometric data ${ }^{7-15}$. 
The present work is designed to investigate the effect of the 2-thiobarbituric acid ligand structure on the stability constants of the complexation of the copper, cobalt, nickel and zinc ions, with due attention to extractions of these ions in some works by 2-thiobarbituric acid ${ }^{16}$.<smiles>O=C1CC(=O)NC(=S)N1</smiles>

\section{Experimental}

Scheme 1. Structure of 2-thiobarbituric acid (TBA).

Acids and bases (all from Merck) were of the highest purity available and were used as received. Deionized water was used throughout the experiment. Analytical grade nitrate salt of ions with the highest purity available was purchased from Merck Company and used without any further purification. 2-Thiobarbituric acid was purchased from Merck Company.

Absorbance measurements were carried out with a Perkin-Elmer UV-Visible spectrophotometer LAMBDA 25. Measurements of $\mathrm{pH}$ were made with a Metrohm $691 \mathrm{pH}-$ meter using a combined glass electrode.

\section{Spectrophotometric titrations}

Standard stock solutions of ligand $\left(1.0 \times 10^{-3} \mathrm{M}\right)$ and the metal ions $\left(1.0 \times 10^{-3} \mathrm{M}\right)$ were prepared by dissolving appropriate weighted amount of pure solid compounds in deionized water and diluted to the mark in $25.0 \mathrm{~mL}$ volumetric flasks. The working solution of ligand was prepared by dilution of the stock solutions with deionized water. The ionic strength was adjusted to $0.2(\% \mathrm{w} / \mathrm{v})$ with $\mathrm{NaCl}$. The $\mathrm{pH}$ was adjusted to 6 . Working solution of metal ions was prepared by dilution of the stock solutions with deionized water. According to the spectra reported in Figures 1-4(a), titration of the ligand solution $\left(1 \times 10^{-5} \mathrm{M}, 2 \mathrm{~mL}\right)$ was carried out by the addition of micro liter amounts of a metal ion in deionized water $\left(5.0 \times 10^{-4} \mathrm{M}\right)$ using a precalibrated micropipette, followed by absorbance intensity reading at $25.0{ }^{\circ} \mathrm{C}$ at the related $\lambda_{\max }$. Since the volume of titrant added during titration was negligible (at the most $0.01 \mathrm{~mL}$ ) as compared with the initial volume of the ligands $(2 \mathrm{~mL})$ and no volume correction was carried out.

\section{Results and Discussion}

Complexation of transition and heavy metal cations are favored by the presence of soft donor atoms such as nitrogen or sulfur, but also ligand containing the harder nitrogen atoms can bind these cations. These ligands, play a key role in the speciation of $\mathrm{Cu}^{+2}, \mathrm{Co}^{+2}, \mathrm{Ni}^{+2}$ and $\mathrm{Zn}^{+2}$ in various media and therefore, in controlling its physicochemical behavior, biological availability, accumulation and mobility. Depending on the $\mathrm{pH}$ value, presence of salts (ionic strength effect) and degree of saturation of binding sites, ligand substances can form either soluble or insoluble complexes with $\mathrm{Cu}^{+2}, \mathrm{Co}^{+2}, \mathrm{Ni}^{+2}$ and $\mathrm{Zn}^{+2}$ and therefore play a double role in various matrixes. In detail, we examined the complexation of metal ions with ligand and their stability constant and complex structure has been calculated using DATAN.

\section{TBA Information}

2-Thiobarbituric acid (Scheme 1) has sulfur, nitrogen and oxygen as donor atoms, allowing them to act as monodentate sulfur donors or oxygen and nitrogen donors. The existence of a donating nitrogen atom as well as $=\mathrm{S}$ group in 2-thiobarbituric acid was expected to increase 
both the stability and selectivity of its ions complex over other metal ions, especially alkali and alkaline earth cations The spectrum of (TBA) in deionized water shows absorption band at $264 \mathrm{~nm}$. As it can be seen from Figure 1-4(a), a decrease in absorbance is observed upon addition of increasing quantities of ions to TBA solution, whereas the absorption intensity changes as a function of the $[\mathrm{L}] /[\mathrm{M}]$ molar ratio (Figure 1-4(b)). These changes could be attributed to the complexation between the ligand and metal ions. From the inflection point in the absorbance/mole ratio plot at values 2 , it can be interpreted that 1:2 $\left(\mathrm{ML}_{2}\right)$ complexes are formed in deionized water solution.

In TBA, due to incorporation and involvement of nitrogen atoms in the ring, the probability for complexation of ion with this ligand through nitrogen atom will be intensively reduced and due to soft-soft interaction of ion with nitrogen higher stability constant and more stable complexes could be obtained.
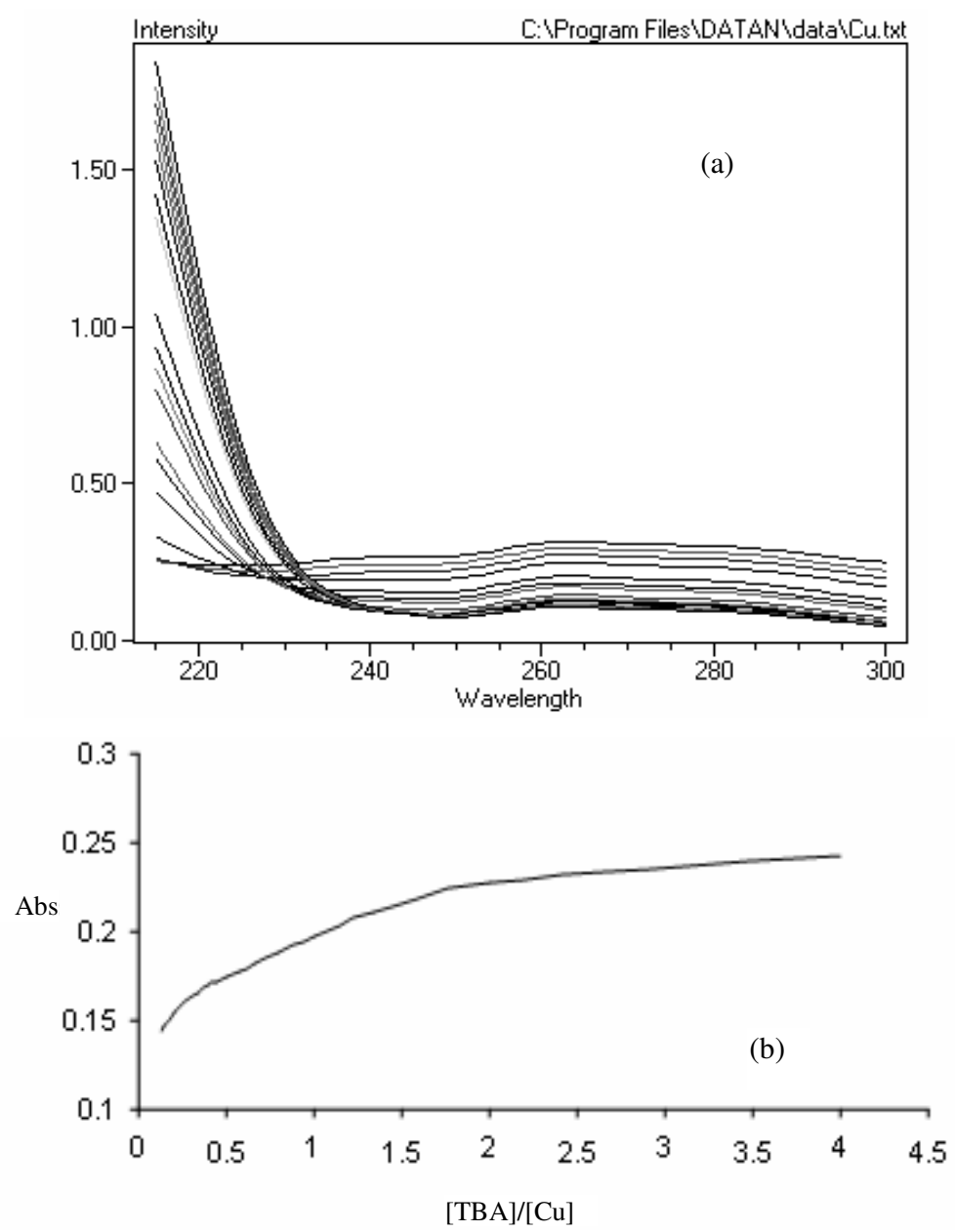

Figure 1. UV-Vis spectra for titration of TBA $\left(1 \times 10^{-5} \mathrm{M}\right)$ with $\mathrm{Cu}^{2+}\left(5 \times 10^{-4} \mathrm{M}\right)$ in deionized water $\left(\mathrm{Ic}=0.2(\% \mathrm{w} / \mathrm{v}), \lambda_{\max }=264 \mathrm{~nm}\right.$, at $\left.\mathrm{T}=25^{\circ} \mathrm{C}\right)(\mathrm{a})$ and the corresponding molar ratio plot (b). 

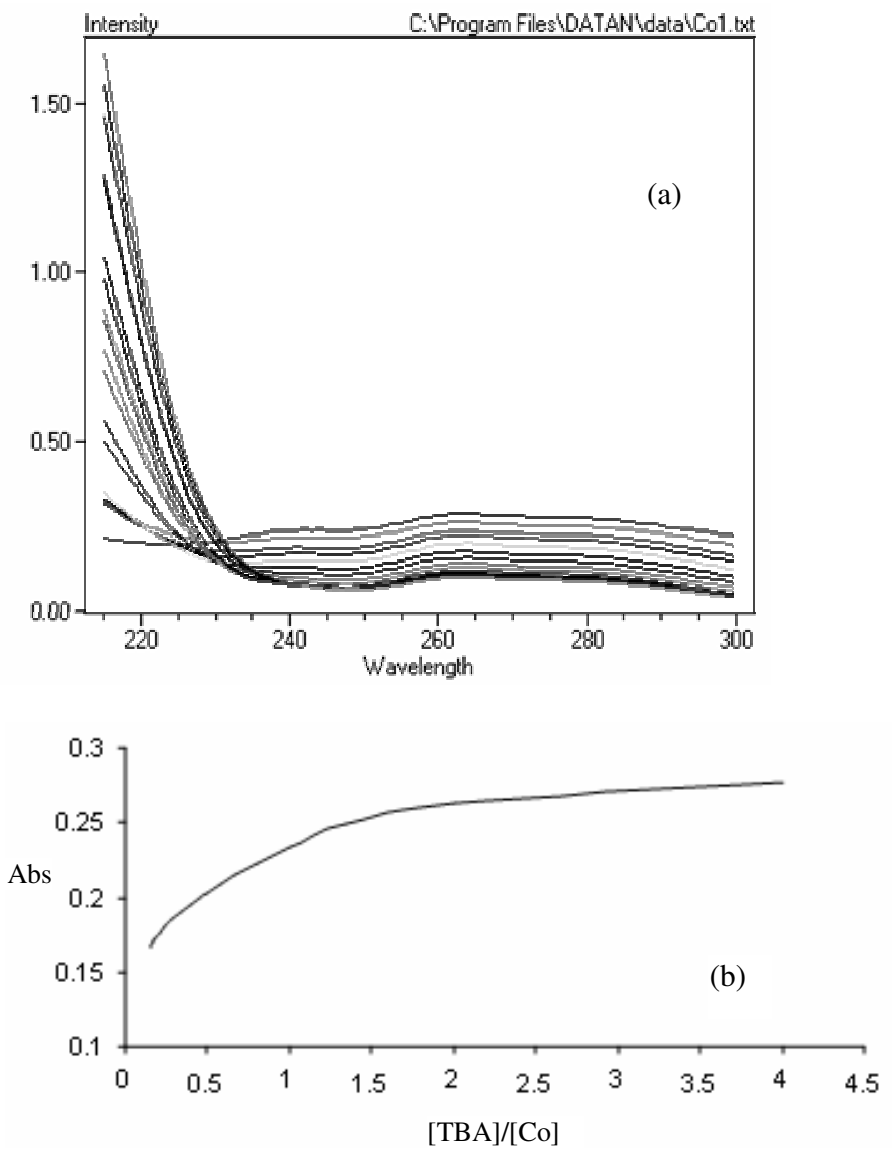

Figure 2. UV-Vis spectra for titration of TBA $\left(1 \times 10^{-5} \mathrm{M}\right)$ with $\mathrm{Co}^{2+}\left(5 \times 10^{-4} \mathrm{M}\right)$ in deionized water (Ic $\left.=0.2(\% \mathrm{w} / \mathrm{v}) \mathrm{NaCl}, \lambda_{\max }=264 \mathrm{~nm}, \mathrm{~T}=25^{\circ} \mathrm{C}, \mathrm{pH}=6\right)$ (a) and the corresponding molar ratio plot (b).

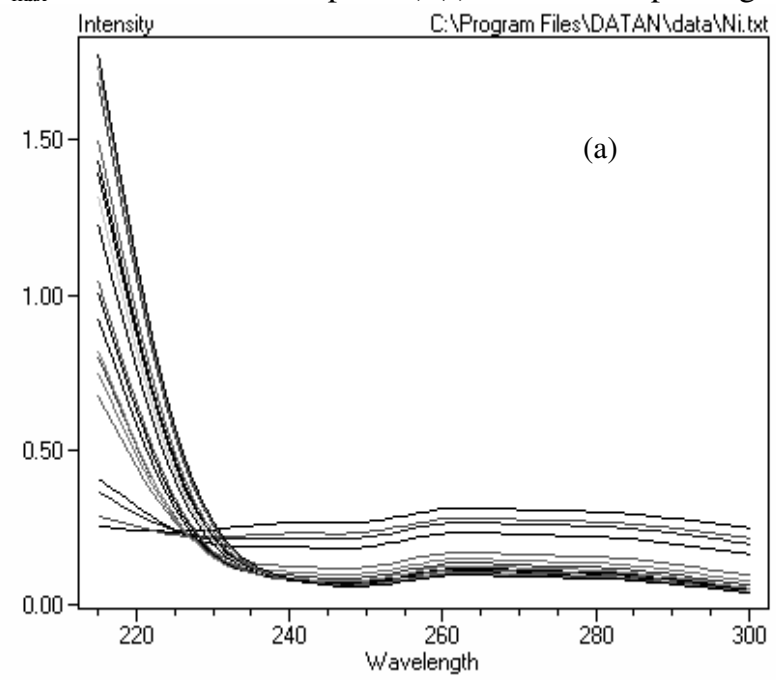




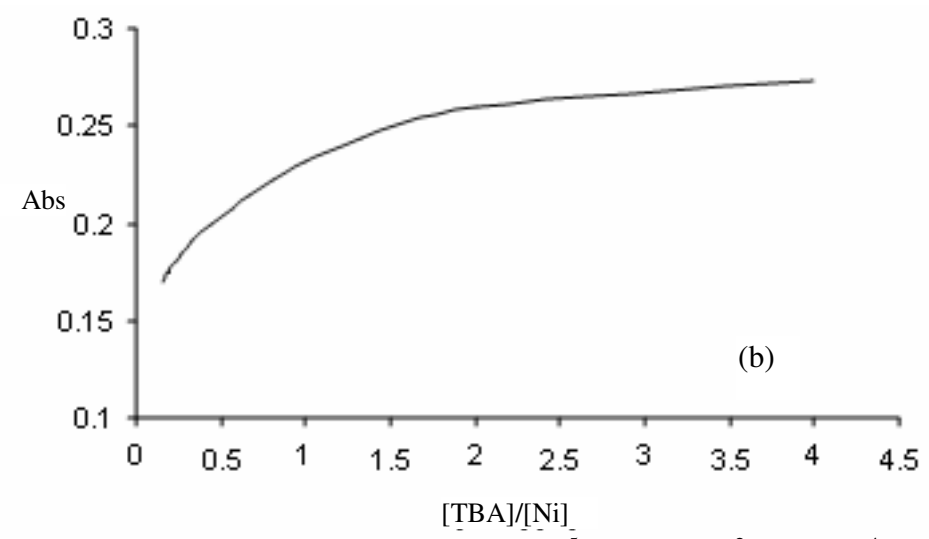

Figure 3. UV-Vis spectra for titration of TBA $\left(1 \times 10^{-5} \mathrm{M}\right)$ with $\mathrm{Ni}^{2+}\left(5 \times 10^{-4} \mathrm{M}\right)$ in deionized water $\left(\mathrm{Ic}=0.2(\% \mathrm{w} / \mathrm{v}) \mathrm{NaCl}, \lambda_{\max }=264 \mathrm{~nm}, \mathrm{~T}=25^{\circ} \mathrm{C}, \mathrm{pH}=6\right)(\mathrm{a})$, and the corresponding molar ratio plot (b).
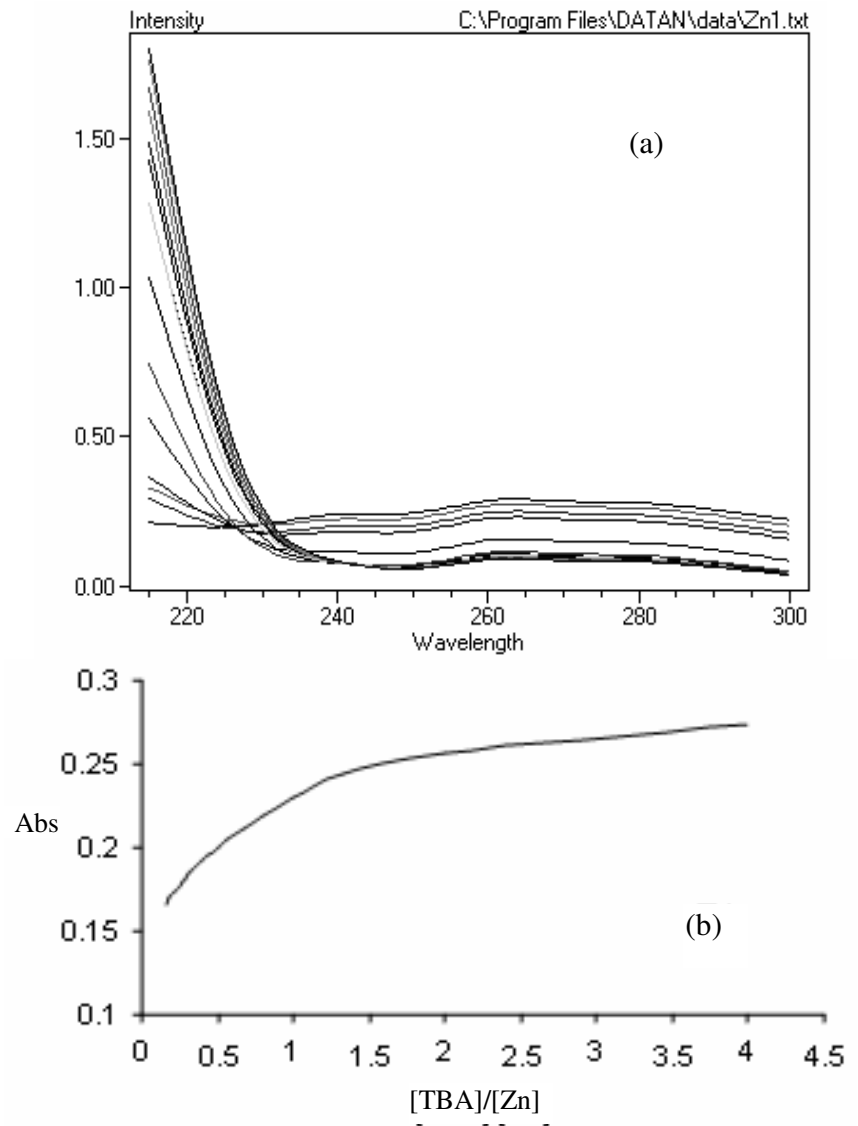

Figure 4. UV-Vis spectra for titration of TBA $\left(1 \times 10^{-5} \mathrm{M}\right)$ with $\mathrm{Zn}^{2+}\left(5 \times 10^{-4} \mathrm{M}\right)$ in deionized water $\left(\mathrm{Ic}=0.2(\% \mathrm{w} / \mathrm{v}) \mathrm{NaCl}, \lambda_{\max }=264 \mathrm{~nm}, \mathrm{~T}=25^{\circ} \mathrm{C}, \mathrm{pH}=6\right)(\mathrm{a})$ and the corresponding molar ratio plot (b). 
Table 1. Logarithm of stability constants assembling for the interaction of metal ions with the TBA at $\mathrm{T}=25^{\circ} \mathrm{C}$, ionic strength of $0.2(\mathrm{w} / \mathrm{v}) \mathrm{NaCl}$ and $\mathrm{pH}=6$ in deionized water.

\begin{tabular}{ccccc}
\hline & \multicolumn{4}{c}{$\log \mathrm{K}$} \\
\cline { 2 - 5 } System & $\mathrm{Cu}^{+2}$ & $\mathrm{Co}^{+2}$ & $\mathrm{Ni}^{+2}$ & $\mathrm{Zn}^{+2}$ \\
$\mathrm{ML}_{2}$ & 4.89 & 4.69 & 4.47 & 4.82 \\
\hline
\end{tabular}

\section{Conclusion}

In the present paper, using DATAN and spectrophotometric data, stability constants of metal ions with TBA ligand have been calculated. The results show the stability of the generated complexes as follows: $\mathrm{Cu}^{+2}>\mathrm{Zn}^{+2}>\mathrm{Co}^{+2}>\mathrm{Ni}^{+2}$. Complexes are in $\mathrm{ML}_{2}$ formation. This ligand can be used in separation methods specially preconcentration methods.

\section{References}

1 Gracia E A and Gomis D B, Mikrochem Acta.,. 1996, 124, 179.

2 Cao S and Zhang M, J Trace Microprobe Tech., 1999, $17,157$.

3 Dwyer F P and Mellor D P, Academic Press Inc: London, UK, 1964.

4 Dye J L and Nicely V A, J Chem Edu., 1971, $48,443$.

$5 \quad$ Martell A E and Motekaitis R J, VCH, Publishers, New York, 1992.

6 Meloun M, Capek J, Miksik P G and Brereton R, Anal Chim Acta., 2000, 423, 51.

7 Seleem H S, El-Shetary B A, Khalil S M E and Shebl M, Serb J Chem.Soc., 2003, 68, 729 .

8 Safavi A and Rastegarzadeh S, Anal Sci.,1999, $15,173$.

9 Moghimi A, Shokrollahi A, Shamsipur M, Aghabozorg H and Ranjbar M, J Mol Struct., 2004, 701, 49.

10 Moghimi A, Shokrollahi A, Shamsipur M Aghabozorg $\mathrm{H}$ and Shockravi A, Inorg Chem., 2003, 42, 1616.

11 Patel R N, Singh N, Shrivastava R P, Shukla K K and Singh P K, Proc Indian Acad Sci (Chem Sci)., 2002, 114, 115.

12 Gao H W and Zhao J F, Croat Chem Acta., 2003, 76,1.

13 Machado C M M, Cukrowski I, Gameiro P and Soares H M V M, Anal Chim Acta., 2003, 493, 105.

14 Bakr M F, J Chin Chem Soc., 2003, 50, 339.

15 Wang Y M, Cheng T H and Liu G C, J Chin Chem Soc., 2000, 47, 1083.

18 Sarrafi A H M, Mirzazdeh M and Ahmadi F, Anal Chem: An Indian J., 2008, 7(9), 1. 


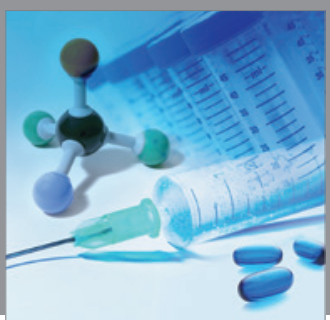

International Journal of

Medicinal Chemistry

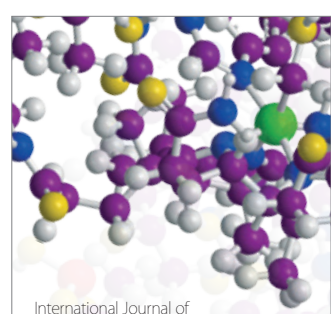

Carbohydrate Chemistry

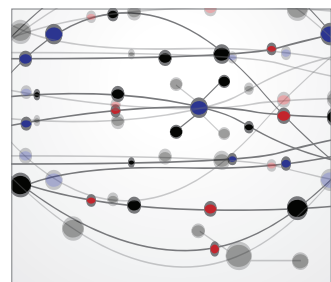

The Scientific World Journal
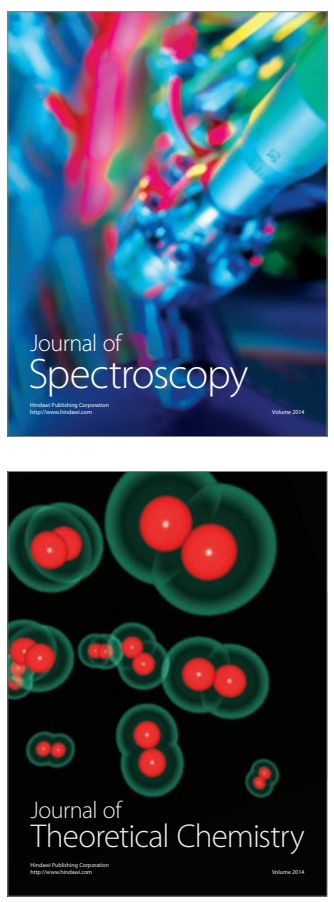
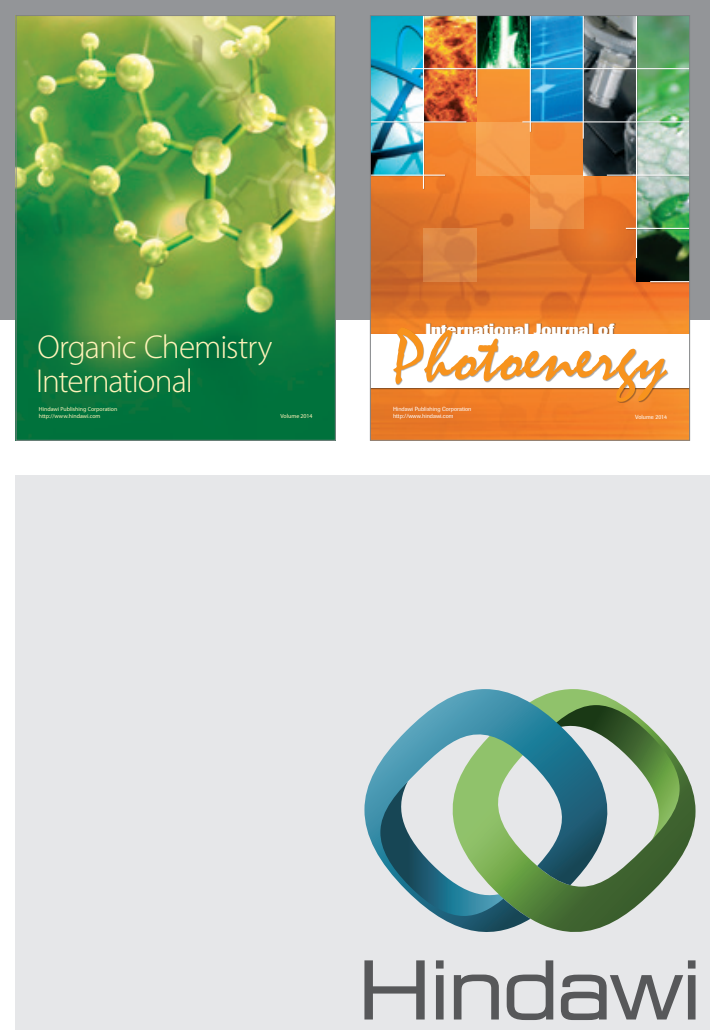

Submit your manuscripts at

http://www.hindawi.com
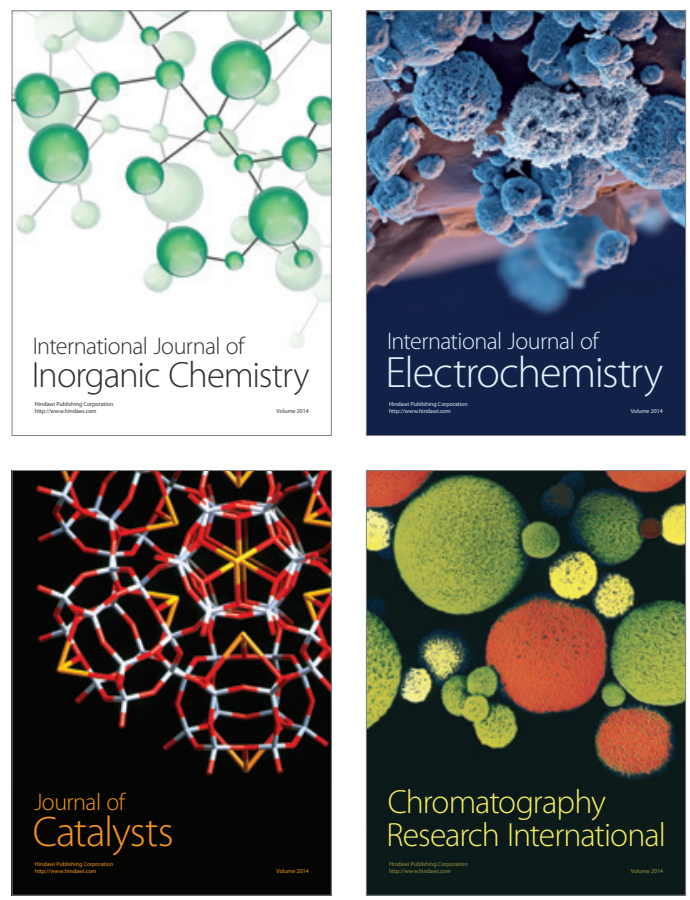
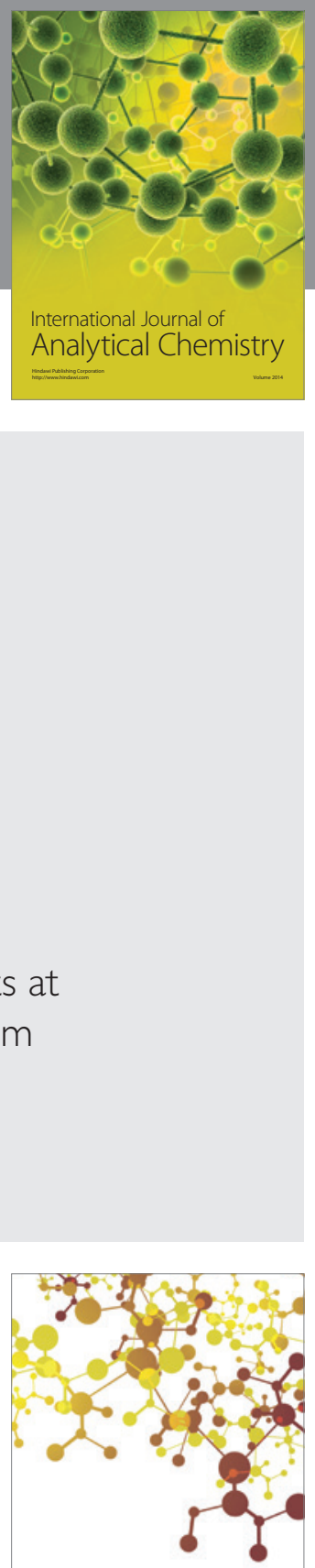

Journal of

Applied Chemistry
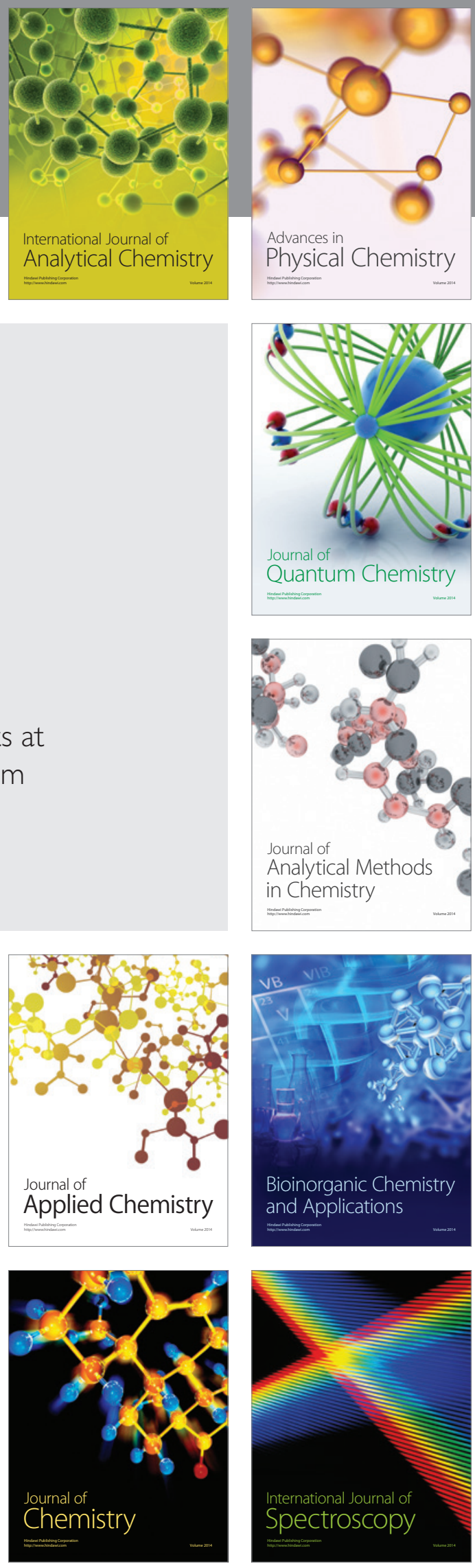